\title{
Effect of the amino-group densities of functionalized ionic liquids on the facilitated transport properties for $\mathrm{CO}_{2}$ separation
}

Shohei Kasahara, ${ }^{\dagger}$ Eiji Kamio, ${ }^{\dagger}$ Abdul Rajjak Shaikh, ${ }^{\dagger}$ Tatsuya Matsuki, ${ }^{\dagger}$ and Hideto Matsuyama ${ }^{*}{ }^{\dagger}$

${ }^{\dagger}$ Center for Membrane and Film Technology, Department of Chemical Science and Engineering, Kobe University, 1-1 Rokkodai-cho, Nada-ku, Kobe, Hyogo 657-8501, Japan

*Corresponding author. Tel: +81-78-803-6180; $\quad$ Fax: +81-78-803-6180; Email: matuyama@kobe-u.ac.jp

\begin{abstract}
Amino acid ionic liquids (AAILs) composed of different sizes and numbers of amino groups, including tetrabutylammonium glycinate, tetramethylammonium glycinate, and 1,1,1-trimethylhydrazinium glycinate, were synthesized as $\mathrm{CO}_{2}$ carriers for facilitated transport membranes. The physical properties of the fabricated AAILs, such as density, viscosity, and $\mathrm{N}_{2}$ and $\mathrm{CO}_{2}$ absorption capacities, were measured, and the fractional free volume was calculated using molecular dynamics (MD) simulations. The results showed that the molar and fractional free volumes decreased with decreasing AAIL size, which caused increased $\mathrm{CO}_{2}$ absorption and decreased $\mathrm{N}_{2}$ absorption. In addition, the $\mathrm{CO}_{2}$ absorption increased with higher numbers of amino groups in the AAILs. The gas permeation properties of facilitated transport membranes containing the synthesized AAILs were investigated. The small AAILs with two amino groups showed better $\mathrm{CO}_{2}$ permeability and $\mathrm{N}_{2}$ barrier properties under humid conditions. We propose that ionic liquids optimized as $\mathrm{CO}_{2}$ carriers for facilitated transport membranes under humid conditions should have high amino-group density, which could be realized by decreasing the molecular size and introducing more amino groups in the molecule.
\end{abstract}

\section{Keywords}

Gas separation, Carbon dioxide, Facilitated transport membrane, Amino acid ionic liquid, Gas absorption properties

\section{Introduction}

With the growing awareness of global warming and serious climate change, energy-efficient and cost-effective technology for $\mathrm{CO}_{2}$ separation is urgently required. The most widely used technology for $\mathrm{CO}_{2}$ separation is an amine-based absorption process. However, aqueous-amine absorption 
processes have disadvantages, including high energy costs, solvent loss, and corrosion effects. Recently, membrane technology has gained importance as a potential alternative to conventional technologies because of its advantages such as low capital and operating costs, low energy consumption, and ease of operation.[1] However, practical application of $\mathrm{CO}_{2}$ separation membranes remains challenging despite extensive research in this field. Poor separation performance, in particular, low $\mathrm{CO}_{2}$ permeability, is a weakness of membranes that restricts their industrial application. The fabrication of a high-performance membrane for $\mathrm{CO}_{2}$ separation would reduce membrane requirements and lead to more compact processing equipment and lower capital costs. The $\mathrm{CO}_{2}$ separation performance is determined by $\mathrm{CO}_{2}$ permeability and other gas barrier properties. Therefore, from a practical perspective, it is necessary to design and fabricate a membrane with high $\mathrm{CO}_{2}$ permeability and other gas barrier properties.

With respect to polymer membranes, a trade-off exists between the $\mathrm{CO}_{2}$ permeability and $\mathrm{CO}_{2}$ selectivity versus other gases; this results in an upper limit to membrane performance.[2] The $\mathrm{CO}_{2}$ separation membranes utilizing ionic liquids as a $\mathrm{CO}_{2}$ separation medium in a membrane, which have attained great attention recently, have the same trade-off and almost same upper limit as the polymer membranes.[3] That is because the $\mathrm{CO}_{2}$ permeation mechanism of the membranes are based on solution-diffusion mechanism. On the other hand, a membrane containing $\mathrm{CO}_{2}$-reactive compounds can achieve very high $\mathrm{CO}_{2}$ permeation through significant enhancement of $\mathrm{CO}_{2}$ absorption while maintaining low permeability to other gases. Such special membranes, which are known as facilitated transport membranes (FTMs), have considerable potential for applications that require good $\mathrm{CO}_{2}$ separation,[4-10] and have shown membrane performance beyond the upper limits.

Recently, we developed a new class of FTM containing amino acid ionic liquids (AAILs), which are a type of amine-functionalized ionic liquid, and reported their excellent $\mathrm{CO}_{2}$ permeability and $\mathrm{CO}_{2} / \mathrm{N}_{2}$ selectivity.[11-14] The advantages of AAILs as a component of FTMs include high $\mathrm{CO}_{2}$ absorption and lack of volatility.[15-17] In addition, the molecular structures of AAILs are flexible for versatile design. Therefore, it is easy to tune the chemical structures of AAILs to be suitable for $\mathrm{CO}_{2}$ transport in FTMs. For example, we proposed an FTM containing an AAIL composed of a compact cation and anion pair. Using the compact AAIL, the $\mathrm{CO}_{2}$ selectivity was successfully improved owing to the considerable $\mathrm{N}_{2}$ barrier properties resulting from the small free volume of the AAIL.[13] From the $\mathrm{CO}_{2}$ permeation perspective, there remain many options to increase the $\mathrm{CO}_{2}$ permeability by tuning the molecular structure of AAILs. Herein, we propose an AAIL with high amino-group density as an effective $\mathrm{CO}_{2}$ carrier in FTMs. Increasing the amino-group density is a promising methodology to enhance both the $\mathrm{CO}_{2}$ absorption and permeability of the FTM.

To enhance the amino-group density, we designed an AAIL composed of a pair of the smallest anion and cation containing amino groups. The compact cation and anion pair not only decreases the 
free volume of the AAIL but also increases the number of amino groups per unit of AAIL volume. Although typical AAILs contain an amino group in the anion, the introduction of an additional amino group in the cation, i.e., dual amino-functionalization, is a straightforward way to increase the amino-group density and $\mathrm{CO}_{2}$ absorption capacity of the AAILs. It was reported that the $\mathrm{CO}_{2}$ absorption of dual amino-functionalized AAILs (dual AAILs), which have two amino groups on the cation and anion, increased two-fold over that of an AAIL with only one amino group in the anion.[18] Accordingly, we synthesized a dual AAIL constructed using small cations and anions on the basis of the above guidelines and investigated the resultant $\mathrm{CO}_{2}$ absorption properties of the dual AAIL and $\mathrm{CO}_{2}$ permeation properties of the dual AAIL-based FTM.

\section{Experimental}

\subsection{Reagents}

Glycinate was chosen as the anion for the AAILs because it is the smallest amino acid. Tetrabutylammonium glycinate $\left(\left[\mathrm{N}_{4444}\right][\mathrm{Gly}]\right)$ was synthesized as a basic AAIL. Tetramethylammonium glycinate $\left(\left[\mathrm{N}_{1111}\right][\mathrm{Gly}]\right)$ and 1,1,1-trimethylhydrazinium glycinate ( $\left[\mathrm{aN}_{111}\right][\mathrm{Gly}]$ ) were used as a small AAIL with low $\mathrm{N}_{2}$ absorption ability and small dual AAIL with high $\mathrm{CO}_{2}$ and low $\mathrm{N}_{2}$ absorption abilities, respectively. The chemical structures of these three AAILs are shown in Fig. 1.

Tetrabutylammonium hydroxide ([ $\left.\mathrm{N}_{4444}\right][\mathrm{OH}], 40 \mathrm{wt} \%$ in water), tetramethylammonium

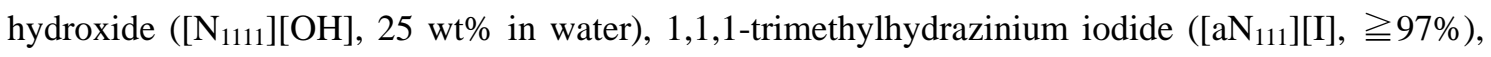
acetonitrile (>99.9\%), and anion exchange resin (OH type) were purchased from Sigma Aldrich (St. Louis, MO, USA). Glycine was purchased from Tokyo Chemical Industry Co. (Tokyo, Japan). Methanol (99.8\%) and ethanol (99.5\%) were purchased from Wako Pure Chemicals Industry Ltd. (Osaka, Japan). All reagents were used as received. [ $\left.\mathrm{N}_{4444}\right][\mathrm{Gly}]$ and $\left[\mathrm{N}_{1111}\right][\mathrm{Gly}]$ were synthesized according to a previously described neutralization procedure (see Supplementary material).[16] [aN $\left.\mathrm{a}_{111}\right][\mathrm{Gly}]$ was synthesized using a previously described anion exchange and neutralization procedure (see Supplementary material).[17] The structures of the resulting [ $\left.\mathrm{N}_{4444}\right][\mathrm{Gly}$ ], $\left[\mathrm{N}_{1111}\right][\mathrm{Gly}]$, and [aN $\left.\mathrm{N}_{111}\right][\mathrm{Gly}]$ products were confirmed by ${ }^{1} \mathrm{H}$ NMR (Bruker Advance 500, Bruker BioSpin, Kanagawa, Japan) and FT-IR (ALPHA FT-IR Spectrometer, Bruker Optics, Tokyo, Japan) spectroscopy (see Supplementary material and Fig. S1).

$\mathrm{CO}_{2}$ and $\mathrm{N}_{2}$ gases with $99.9 \%$ purity were used for the gas permeation tests. A hydrophilic polytetrafluoroethylene (PTFE) microporous membrane with an average pore size of $0.1 \mu \mathrm{m}$ and film thickness of $37.5 \mu \mathrm{m}$ was purchased from Sumitomo Electric Industries Ltd. (Osaka, Japan) and used as a support for the AAIL-based membranes.

\subsection{Physicochemical properties of the AAILs}




\subsubsection{Density and viscosity measurements}

Samples for density and viscosity measurements were prepared by drying the synthesized AAILs for $12 \mathrm{~h}$ at $343 \mathrm{~K}$. The densities of the AAILs were measured using a density/specific gravity meter (DA-650, Kyoto Electronics Manufacturing Co., Ltd., Kyoto, Japan). The densities were measured at temperatures in the range of 303 to $363 \mathrm{~K}$.

The viscosities of the AAILs were measured using an electromagnetically spinning sphere (EMS) viscometer (EMS-1000W, Kyoto Electronics Manufacturing Co., Ltd.) using a metallic sphere at a constant rotation speed of $1000 \mathrm{rpm}$. Using the EMS viscometer, the viscosity of the liquids in an environment with the desired gas composition in which the liquids absorbed the contacting gases can be measured. In this study, the viscosities of the AAILs in contact with humid $\mathrm{CO}_{2}$ in a sample vessel were continuously measured. For the measurements, the gas inlet and outlet channels were placed at the top of the sample vessel. A schematic illustration of the viscosity measurement system is shown in Fig. 2.

For the viscosity measurements of the AAILs in the absence of $\mathrm{CO}_{2}$, a certain portion of the AAIL sample was introduced into the vessel, and then the gas inlet and outlet channels were closed. For the investigation of the temperature, dried AAILs were used. The measurements were carried out at temperatures in the range of 303 to $373 \mathrm{~K}$. The effect of the water content of the AAILs was investigated using AAILs containing a certain amount of pure water. The measurements were performed at $373 \mathrm{~K}$.

During the investigation of the effect of water vapor on the viscosities of $\mathrm{CO}_{2}$-absorbed AAILs, the viscosity was continuously measured during subsequent introductions of dry and humid $\mathrm{CO}_{2}$. In this case, the inlet and outlet channels were opened, and the gas was continuously introduced into the sample vessel. The concentration of $\mathrm{CO}_{2}$ and relative humidity $(\mathrm{RH})$ of the humid gas was adjusted by controlling the flow rate of $\mathrm{CO}_{2}$ and water vapor using a mass-flow controller (Hemmi Slide Rule Co, Ltd., Tokyo, Japan) and a reciprocating metering pump (Nihon Seimitsu Kagaku Co. Ltd., Japan), rspectively. The RH of the gas was adjusted by introducing the desired amount of water, which was completely vaporized. The experiments were carried out at $373 \mathrm{~K}$.

\subsubsection{Gas absorption properties of the AAILs}

The apparatus used to measure the gas absorption isotherms is illustrated in Fig. 3. This apparatus has a water injection port to measure the gas absorption under saturated water vapor conditions. The temperature of the system was controlled by a water bath (T-105B, Thomas Kagaku Co., Ltd., Tokyo, Japan) with an accuracy of $\pm 0.1 \mathrm{~K}$. The pressure was monitored by a digital pressure gauge (MODEL AM-756 digital manometer, GE Sensing \& Inspection Technologies Co., Ltd., Tokyo, Japan). The equipment consisted of stainless steel tubes along with reference and sample cells. The volumes of both the reference and sample cells were determined before the 
absorption experiments.[14] In this study, $\mathrm{CO}_{2}$ and $\mathrm{N}_{2}$ absorption tests were carried out under different conditions. Each test was conducted according to the following procedures.

\subsubsection{1 $\mathrm{CO}_{2}$ absorption tests}

The $\mathrm{CO}_{2}$ absorption test was carried out at $343 \mathrm{~K}$ at $100 \% \mathrm{RH}$. Initially, AAIL (1.5 g) was added to the sample cell. The reference and sample cells were evacuated, and the valve separating the two cells was then closed. A known amount of water that was sufficient to achieve $100 \%$ RH was added to the reference cell. The pressure was monitored until it became constant. The pressure increase was confirmed to be equal to the saturated water vapor pressure. The valve separating the two cells was then opened to allow contact between the water vapor and AAIL. After the AAIL fully absorbed the water vapor, the valve was closed. The remaining amount of water in the reference cell was calculated from the amount of water added and saturated water vapor pressure, and the actual volume of the cells excluding water was recalculated. The reference cell was then pressurized to the desired pressure by introducing $\mathrm{CO}_{2}$ from a $\mathrm{CO}_{2}$ cylinder. After the $\mathrm{CO}_{2}$ was charged, the stirrer was turned on, and the AAIL was stirred at a constant rate throughout the experiment. $\mathrm{CO}_{2}$ absorption began when the valve connecting the two cells was opened. Once the valve was open, the $\mathrm{CO}_{2}$ in the reference cell transferred into the sample cell, bringing the $\mathrm{CO}_{2}$ into contact with the AAIL. This mixing led to a drop in pressure caused by absorption of $\mathrm{CO}_{2}$ by the AAIL. The pressure was monitored until it remained constant for more than $1 \mathrm{~h}$, with equilibration generally achieved within $3 \mathrm{~h}$. After the system reached equilibrium, the final pressure was measured, and the amount of $\mathrm{CO}_{2}$ absorption was determined from the observed pressure change.

\subsubsection{2 $\mathrm{N}_{2}$ absorption tests}

In this study, we focused on the $\mathrm{CO}_{2}$ permeation properties of AAIL-FTMs under humid conditions. Therefore, it was preferable to measure the $\mathrm{N}_{2}$ absorption properties under humid conditions. However, under humid conditions, both water and nitrogen are present in the system. Because the $\mathrm{N}_{2}$ absorption of the AAILs was quite low, the pressure drop upon $\mathrm{N}_{2}$ absorption would also be very small. Therefore, the relative pressure fluctuation caused by water evaporation and condensation cannot be neglected; accordingly, we cannot accurately measure the amount of $\mathrm{N}_{2}$ absorbed under humid conditions. Hence, the $\mathrm{N}_{2}$ absorption tests were carried out under dry conditions.

The $\mathrm{N}_{2}$ absorption test was performed at $343 \mathrm{~K}$. A known amount of the AAIL was added to the sample cell, and the $\mathrm{N}_{2}$ absorption test was carried out using a similar procedure to that used for the $\mathrm{CO}_{2}$ absorption test, except that no water was added.

\subsection{Molecular dynamics simulations to evaluate absorption under humid conditions}

Owing to the experimental limitations described above, we could not investigate the $\mathrm{N}_{2}$ absorption of each AAIL under humid conditions. However, it is important to determine the $\mathrm{N}_{2}$ 
absorption under humid conditions in order to confirm our proposed guideline for the structure of AAILs with superior $\mathrm{N}_{2}$ barrier properties. It has been reported that the amount of $\mathrm{N}_{2}$ physically absorbed in room temperature ionic liquids (RTILs) correlated well with the free volume of ionic liquids.[19, 20] Thus, we calculated the fractional free volume (FFV) using MD simulations and investigated the amount of $\mathrm{N}_{2}$ absorbed in the AAILs under humid conditions. The relationship between the amount of $\mathrm{N}_{2}$ absorbed and FFV of the AAILs was presumed via the relationship under dry conditions.

The structures were built using Material Studio version 6.1.[21] Quantum chemistry calculations were performed using the Gaussian 09 program.[22] Vibrational analyses of all calculated structures revealed a lack of imaginary frequencies, confirming the presence of true minima on the potential energy surface. The electrostatic potential surface was generated by the Merz-Kollman method at an HF/6-31G(d) level of theory, which is typical for Amber-like force fields, followed by multiconfigurationally two-stage relaxed electrostatic potential (RESP) fitting. The software code R. E. D. IV was used for the RESP fitting.[23] We used the Amber force field to determine the intraand inter-molecular force constants for the cations and anions of the ionic liquids.[24]

\subsubsection{Simulation details}

We generated initial configurations of the ionic liquid using the Packmol program.[25] All simulations reported here were performed using the Gromacs 4.5 simulation program.[26] The simulated systems were composed of 384 ion pairs. Under humid conditions, we added 384 water molecules to the ionic mixture using Packmol. The configurations were then optimized by Gromacs using an energy minimization routine. The MD simulations were performed at $300 \mathrm{~K}$ for the neat ionic liquid to reproduce the experimental density and validate the model. Production simulations were carried out using the isothermal-isobaric (NPT) ensemble for 25 ns. The temperature and pressure were controlled with coupling times of 5 and 1 ps using the velocity-scaling [27] and Berendsen methods [28], respectively. The equations of motion were integrated with the leapfrog algorithm with a time step of 2.0 fs. The full electrostatic interactions were accounted for using the particle mesh Ewald summation.[29] Coulomb and van der Waals cutoffs of $1.2 \mathrm{~nm}$ were used. Periodic boundary conditions in all directions were used to mimic the bulk behavior. The bond lengths were constrained with the LINCS algorithm. After the simulation, the physical properties were characterized using Gromacs analysis tools, and the structures were visualized by visual molecular dynamics.[30] A similar procedure was followed for the ionic liquid-water mixtures.

\subsubsection{Binding energy calculations}

To investigate the strengths of the interactions between the cations and anions in the gas and solvent phases, density functional theory (DFT) calculations were carried out with the B3LYP 
functional and 6-31+G(d,p) basis set using the Gaussian 09 program.[22] Different possible orientations of the cation and anion interactions were considered, and the minimum energy conformation was selected for the single-point energy calculations. Frequency calculations were performed to ensure that the ionic pairs were indeed at their minimum energy. Starting with an optimized geometry, single-point energy calculations were carried out using the $6-311+G(3 \mathrm{df}, 2 \mathrm{p})$ basis set and M05-2X functional routine. Previous studies have demonstrated that the DFT method is suitable for calculations on ILs using the method described above.[31, 32] The solvent effects were mimicked using the SMD solvation model.[33]

\subsubsection{Free volume calculations}

The equilibrated structures obtained after the MD simulations were selected for FFV calculations. The FFV was calculated using the following method:[34]

$$
F F V=\frac{V_{m}-V_{v d W}}{V_{m}}
$$

where $V_{\mathrm{vdW}}$ is the van der Waals volume of the molecule and $V_{\mathrm{m}}$ is the molar volume. The van der Waals radii according to Bondi were used for this calculation and were calculated using the Material Studio program.[21, 35]

\subsection{Gas permeability measurements}

The AAIL-based membranes were prepared as follows. A hydrophilic PTFE microporous membrane was immersed into the synthesized AAILs, i.e., [ $\left.\mathrm{N}_{4444}\right][\mathrm{Gly}],\left[\mathrm{N}_{1111}\right][\mathrm{Gly}]$, and [aN $\left.\mathrm{a}_{111}\right][\mathrm{Gly}]$, and immediately decompressed for $1 \mathrm{~h}$ to allow complete exchange of the air in the PTFE membrane with the ionic liquid. The AAIL-impregnated PTFE membrane was removed, and the excess AAIL on the surface was wiped off.

The gas permeabilities of the AAIL-based membranes were measured according to a previously reported procedure.[11-14] In this study, the $\mathrm{CO}_{2}$ partial pressure and relative humidity dependencies on the gas permeability was examined using the apparatus shown in Fig. 4. Details of the experimental procedure are described in the Supplementary material. The experimental conditions are listed in Table 1.

\section{Results and discussion}

3.1 Densities, molar volumes, and viscosities of the synthesized AAILs

It has been reported that the $\mathrm{N}_{2}$ permeabilities of the AAIL-based FTMs as well as amounts of $\mathrm{N}_{2}$ absorbed by AAILs depend strongly on the molar volume and free volume of the AAILs.[13] We also previously reported that the $\mathrm{CO}_{2}$ permeabilities of AAIL-based FTMs increased with decreasing size of the AAILs.[13] Accordingly, it was suggested that the amount of $\mathrm{CO}_{2}$ absorbed in the AAILs 
increases with decreasing size of AAILs, which leads to an increase in the amount of amino groups per unit volume of AAILs. To evaluate the effect of the molecular sizes of the AAILs on their $\mathrm{CO}_{2}$ and $\mathrm{N}_{2}$ absorption, their molar densities and molar volumes were investigated. The densities of the AAILs at various temperatures were measured and their molar densities and molar volumes were calculated.

Fig. 5(a) shows the effect of temperature on the molar density of the AAILs. As shown in Fig. 5(a), the molar densities of the AAILs were in the following order: $\left[\mathrm{aN}_{111}\right][\mathrm{Gly}] \approx\left[\mathrm{N}_{1111}\right][\mathrm{Gly}]>$ $\left[\mathrm{N}_{4444}\right][\mathrm{Gly}]$. If each type of AAIL molecule has the same number of amino groups, this order would directly relate to the order of amino-group density in the AAILs. However, the number of amino groups per molecule of [ $\left.\mathrm{aN}_{111}\right][\mathrm{Gly}]$ is twice that of the others. Therefore, the amino-group densities of the AAILs are in the following order: $\left[\mathrm{aN}_{111}\right][\mathrm{Gly}]>\left[\mathrm{N}_{1111}\right][\mathrm{Gly}]>\left[\mathrm{N}_{4444}\right][\mathrm{Gly}]$. If all the amino groups in each AAIL can react with $\mathrm{CO}_{2}$, the amount of $\mathrm{CO}_{2}$ absorbed in the AAILs should follow the same order as the amino-group density of the AAILs.

The molar volumes of the AAILs, which would strongly affect $\mathrm{N}_{2}$ absorption, are shown in Fig. 5(b). $\left[\mathrm{N}_{4444}\right][\mathrm{Gly}]$, which has a large cation, showed the highest molar volume at all temperatures. The molar volumes of [ $\left.\mathrm{N}_{1111}\right][\mathrm{Gly}]$ and $\left[\mathrm{aN} \mathrm{N}_{111}\right][\mathrm{Gly}]$ were similar because the sizes of $\left[\mathrm{N}_{1111}\right]^{+}$and $\left[\mathrm{aN}_{111}\right]^{+}$are similar. From these results, it can be predicted that the amount of $\mathrm{N}_{2}$ absorbed in the AAILs would be in the following order: [ $\left.\mathrm{N}_{4444}\right][\mathrm{Gly}]>\left[\mathrm{N}_{1111}\right][\mathrm{Gly}] \approx\left[\mathrm{aN}_{111}\right][\mathrm{Gly}]$.

The viscosities of the AAILs, which strongly affect the diffusivity of gases in AAIL-based FTMs, also affect the membrane performance when AAILs are used as the $\mathrm{CO}_{2}$ carrier in FTMs. Figs. 6(a) and (b) show the effect of temperature and water content of the AAILs, respectively, on their viscosity. As shown in Figs. 6(a) and (b), the viscosities of the AAILs decreased with increasing temperature or water content of the AAILs and were in the following order: [ $\left.\mathrm{N}_{4444}\right][\mathrm{Gly}]>$ $\left[\mathrm{aN}_{111}\right][\mathrm{Gly}]>\left[\mathrm{N}_{1111}\right][\mathrm{Gly}]$. In previous studies, it was revealed that the viscosities of AAILs after $\mathrm{CO}_{2}$ absorption were dramatically higher than those of neat AAILs under dry conditions around room temperature.[14] The dramatic increase of the viscosity along with $\mathrm{CO}_{2}$ absorption would be due to the formation of an intermolecular hydrogen bond network among the AAIL-CO complexes.[14, 36, 37] Therefore, the viscosity of the AAIL in contact with $\mathrm{CO}_{2}$ was the dominant factor in determining the $\mathrm{CO}_{2}$ permeation properties of AAIL-FTMs when used under dry conditions around room temperature. However, under humid conditions, the intermolecular hydrogen bonding would be weakened by intercalation of water between the complexes. Therefore, it is expected that, under humid conditions, the marked increase in viscosity of the AAIL-CO ${ }_{2}$ complex would be prevented. In this study, we investigated the effect of the RH on the viscosities of AAILs during contact with $\mathrm{CO}_{2}$. The viscosity change of $\left[\mathrm{aN}_{111}\right][\mathrm{Gly}]$ was measured with changing water vapor content in $\mathrm{CO}_{2}$, and the results are shown in Fig. 7. As shown in Fig. 7, the viscosity of [aN $\left.\mathrm{a}_{11}\right][\mathrm{Gly}]$ gradually increased during contact with pure $\mathrm{CO}_{2}$; this was due to the formation of $\mathrm{CO}_{2}$-[aN $\left.\mathrm{an}_{11}\right][\mathrm{Gly}]$ 
complexes and a hydrogen bonding network between the complexes. However, upon the introduction of water vapor, the viscosity drastically decreased. This was caused by destruction of the hydrogen bonding networks between the complexes because of the intercalation of water molecules. From these results, the AAIL-based FTMs would preferably be used under humid conditions.

\subsection{Gas absorption tests}

\subsection{1 $\mathrm{N}_{2}$ absorption}

Applications of AAILs in $\mathrm{CO}_{2}$ separation membranes involve the presence of $\mathrm{CO}_{2}, \mathrm{~N}_{2}$, and water vapor around the AAILs. It is therefore reasonable to measure the amount of gas absorbed by the AAILs under such conditions to elucidate the $\mathrm{CO}_{2}$ and $\mathrm{N}_{2}$ permeation properties from the gas absorption abilities. However, we cannot accurately measure the amount of $\mathrm{N}_{2}$ absorbed in the AAILs under such conditions, as described above. In this study, therefore, we calculated the FFVs of the AAILs via MD simulations and discussed the $\mathrm{N}_{2}$ absorption in light of the computational results.

The FFVs and densities of the AAILs calculated from MD simulations, $\rho_{\text {calced, }}$ are listed in Table 2. First, to check the validity of the computational results, the densities before $\mathrm{CO}_{2}$ absorption calculated from the simulation under dry conditions were compared with the experimental results; from Table 2, it is evident that the calculated and experimental densities of the neat AAILs at $300 \mathrm{~K}$ are nearly equal. Thus, it was confirmed that the computational results calculated in this study were reasonable.

Subsequently, we considered the FFVs of the AAILs shown in Table 2. Before $\mathrm{CO}_{2}$ absorption under dry conditions, $\left[\mathrm{N}_{4444}\right][\mathrm{Gly}]$ had the highest FFV, i.e., about 1.6 times larger than those of $\left[\mathrm{N}_{1111}\right][\mathrm{Gly}]$ and $\left[\mathrm{aN}_{111}\right][\mathrm{Gly}]$. In the case of $\left[\mathrm{N}_{1111}\right][\mathrm{Gly}]$ and $\left[\mathrm{aN}_{111}\right][\mathrm{Gly}]$, the FFVs were very similar. To investigate the relationship between the FFV and amount of $\mathrm{N}_{2}$ absorbed, the computational results for the FFVs under dry conditions were compared with the experimentally obtained $\mathrm{N}_{2}$ absorption amounts measured under dry conditions. The FFVs have been reported to correlate with the molar amount of $\mathrm{N}_{2}$ absorbed per unit volume of RTIL.[19] Therefore, we used the following units to describe the amount of $\mathrm{N}_{2}$ absorbed in the AAILs: mol- $\mathrm{N}_{2} / \mathrm{dm}^{3}$-AAIL. As shown in Fig. 8(a), $\left[\mathrm{N}_{4444}\right][\mathrm{Gly}]$ absorbed the most $\mathrm{N}_{2}$, i.e., about 1.9 times more than those of the other AAILs. [ $\left.\mathrm{N}_{1111}\right][\mathrm{Gly}]$ and [aN $\left.\mathrm{N}_{111}\right][\mathrm{Gly}]$ absorbed very similar amounts of $\mathrm{N}_{2}$. These tendencies were almost the same as those of the FFVs under dry conditions. From these results, it was confirmed that the amounts of $\mathrm{N}_{2}$ absorbed strongly correlated with the FFVs of the AAILs. This correlation between FFV and amount of $\mathrm{N}_{2}$ absorbed should also occur under humid conditions. Therefore, the amounts of $\mathrm{N}_{2}$ absorbed by [ $\left.\mathrm{N}_{4444}\right][\mathrm{Gly}]$, [ $\left.\mathrm{N}_{1111}\right][\mathrm{Gly}]$, and [aN $\left.\mathrm{N}_{111}\right][\mathrm{Gly}]$ after $\mathrm{CO}_{2}$ absorption under humid conditions were then investigated under humid conditions. As shown in Table 2, the FFVs of the AAIL- $\mathrm{CO}_{2}$ complexes formed after $\mathrm{CO}_{2}$ absorption under humid conditions were in the 
following order: $\left[\mathrm{N}_{4444}\right][\mathrm{Gly}]>\left[\mathrm{aN}_{111}\right][\mathrm{Gly}] \approx\left[\mathrm{N}_{1111}\right][\mathrm{Gly}]$. Hence, the amounts of $\mathrm{N}_{2}$ absorbed under humid conditions would also be in that order. From these results, it is evident that the amount of $\mathrm{N}_{2}$ absorbed in the AAILs after $\mathrm{CO}_{2}$ absorption under humid conditions could be reduced by decreasing the size of the AAILs.

\subsection{2 $\mathrm{CO}_{2}$ absorption}

Figs. 8(b) and (c) show the amounts of $\mathrm{CO}_{2}$ absorbed by [ $\left.\mathrm{N}_{4444}\right][\mathrm{Gly}],\left[\mathrm{N}_{1111}\right][\mathrm{Gly}]$, and [aN $\left.\mathrm{a}_{111}\right]$ [Gly] at $100 \% \mathrm{RH}$. In this study, we attempted to increase the amount of $\mathrm{CO}_{2}$ absorbed by AAILs by increasing the number of amino groups per unit volume of AAIL, i.e., amino-group density. As mentioned before, the amino-group densities of the AAILs synthesized in this study are in the following order: $\left[\mathrm{aN}_{111}\right][\mathrm{Gly}]>\left[\mathrm{N}_{1111}\right][\mathrm{Gly}]>\left[\mathrm{N}_{4444}\right][\mathrm{Gly}]$. Therefore, if all of the amino groups in the AAILs reacted with $\mathrm{CO}_{2}$, the amounts of $\mathrm{CO}_{2}$ absorbed by the AAILs should be in the same order. The $\mathrm{CO}_{2}$ absorption isotherms for each AAIL are shown in Fig. 8(b). [ $\left.\mathrm{N}_{1111}\right][\mathrm{Gly}]$ absorbed more $\mathrm{CO}_{2}$ than $\left[\mathrm{N}_{4444}\right][\mathrm{Gly}]$, which is in agreement with the prediction from the molar densities of these AAILs. Here, it is worth noting that the amount of $\mathrm{CO}_{2}$ absorbed by [aN $\left.\mathrm{N}_{111}\right][\mathrm{Gly}]$ was higher than that absorbed by $\left[\mathrm{N}_{1111}\right][\mathrm{Gly}]$; this results from the dual amino-functionalized effect

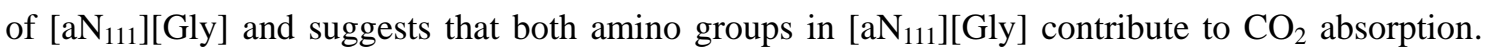
The effect of dual amino-functionalization on the amount of $\mathrm{CO}_{2}$ absorbed can be easily evaluated by comparing the molar amount of $\mathrm{CO}_{2}$ absorbed per unit mole of the AAILs. As shown in Fig. 8(c), [aN $\left.{ }_{111}\right]$ [Gly] exhibited the highest $\mathrm{CO}_{2}$ absorption because of the presence of two amino groups in each molecule. On the other hand, the $\mathrm{CO}_{2}$ absorptions of $\left[\mathrm{N}_{1111}\right][\mathrm{Gly}]$ and $\left[\mathrm{N}_{4444}\right][\mathrm{Gly}]$ were approximately equal; this shows that the amino groups in $\left[\mathrm{N}_{1111}\right][\mathrm{Gly}]$ and $\left[\mathrm{N}_{4444}\right][\mathrm{Gly}]$ have the same $\mathrm{CO}_{2}$ absorption properties. From these results, the superior $\mathrm{CO}_{2}$ absorption properties of the dual amino-functionalized ionic liquid were confirmed.

Based on the above results, [aN $\left.\mathrm{aN}_{111}\right][\mathrm{Gly}]$ has suitable gas-absorption properties for application as a carrier in $\mathrm{CO}_{2}$ separation membranes. It is expected that [aN$\left.{ }_{111}\right][\mathrm{Gly}]$-based FTMs would have better $\mathrm{CO}_{2}$ permeation properties than $\left[\mathrm{N}_{4444}\right][\mathrm{Gly}]$ - and [ $\left.\mathrm{N}_{1111}\right][\mathrm{Gly}]$-based FTMs.

\subsection{Gas permeation properties of AAIL-FTMs}

To confirm the facilitated transport mechanism of the [aN $\left.{ }_{111}\right][\mathrm{Gly}]$-based FTM, we examined the $\mathrm{CO}_{2}$ partial pressure dependency on the $\mathrm{CO}_{2}$ permeability. As shown in Fig. 9(a), the $\mathrm{CO}_{2}$ permeability strongly depended on the $\mathrm{CO}_{2}$ partial pressure. This behavior is a general trend of FTMs which is caused by the saturation of $\mathrm{CO}_{2}$ carrier under high $\mathrm{CO}_{2}$ partial pressure conditions. From this result, it was confirmed that $\left[\mathrm{aN}_{111}\right][\mathrm{Gly}]$-based FTM permeated $\mathrm{CO}_{2}$ based on the facilitated transport mechanism. On the other hand, as shown in Fig. 9(b), the $\mathrm{N}_{2}$ permeability was not depended on the $\mathrm{CO}_{2} / \mathrm{N}_{2}$ mixed gas composition because the $\mathrm{N}_{2}$ permeation through the 
membrane was based on solution-diffusion mechanism. Regarding the $\mathrm{CO}_{2}$ permeability around 10 $\mathrm{kPa}$ of $\mathrm{CO}_{2}$ partial pressure, it remained about 1000 barrer with about 50 of $\mathrm{CO}_{2} / \mathrm{N}_{2}$ selectivity as shown in Fig. 9(a) and (c), respectively. It is worthy to note that the $\mathrm{CO}_{2}$ flux of the membrane in whole $\mathrm{CO}_{2}$ partial pressure range investigated in this study was not depended on the $\mathrm{CO}_{2}$ partial pressure at all. In the practical operation using a membrane module, the $\mathrm{CO}_{2}$ partial pressure in the feed gas continuously decreased along with the $\mathrm{CO}_{2}$ permeation in the membrane module from the upstream to the downstream because of the $\mathrm{CO}_{2}$ permeation. In the case using normal $\mathrm{CO}_{2}$ separation membrane of which $\mathrm{CO}_{2}$ permeation is based on solution-diffusion mechanism, the $\mathrm{CO}_{2}$ flux continuously decreases with the decrease of the $\mathrm{CO}_{2}$ partial pressure in the module. However, [aN $\left.\mathrm{a}_{111}\right][\mathrm{Gly}]$-based FTM can keep its $\mathrm{CO}_{2}$ flux in spite of the decrease of $\mathrm{CO}_{2}$ partial pressure. That means the $\mathrm{CO}_{2}$ flux could be kept constant in whole position in the membrane module. This is advantageous property to make the process simple.

To confirm the effect of amino group introduced in the cation of the [aN $\left.\mathrm{a}_{111}\right][\mathrm{Gly}]$, the gas permeation performances of the $\left[\mathrm{aN}_{111}\right][\mathrm{Gly}]$-based FTMs were tested under humid conditions and compared with those of the $\left[\mathrm{N}_{1111}\right][\mathrm{Gly}]$ - and [ $\left.\mathrm{N}_{4444}\right][\mathrm{Gly}]$-based FTMs. Under humid conditions, the hydrogen bonding networks between AAIL- $\mathrm{CO}_{2}$ complexes would be only loosely formed. As a result, with increasing the humidity, the viscosities of the AAILs after $\mathrm{CO}_{2}$ absorption would gradually decrease and become almost constant under highly humid conditions. In other words, under highly humid conditions, the gas absorption properties, and not $\mathrm{CO}_{2}$-complex diffusion, play a key role in determining the $\mathrm{CO}_{2}$ separation properties of the AAIL-FTMs.

As shown in Fig. 10(a), the $\mathrm{CO}_{2}$ permeabilities of all AAILs increased with increasing $\mathrm{RH}$ at low $\mathrm{RH}$ ranges. These results suggest that the dominant factor that affects $\mathrm{CO}_{2}$ permeation is trans-membrane diffusion of the $\mathrm{CO}_{2}$ complex because of the relatively high viscosity under low $\mathrm{RH}$ conditions. On the other hand, under high $\mathrm{RH}$ conditions, the $\mathrm{CO}_{2}$ permeation properties were significantly different for the AAIL types used. The $\mathrm{CO}_{2}$ permeabilities of the FTMs containing $\left[\mathrm{N}_{1111}\right][\mathrm{Gly}]$ and [ $\left.\mathrm{N}_{4444}\right]$ [Gly] were almost constant above 50\% RH. Under high RH conditions, the water contents of the AAILs increased above $10 \mathrm{wt} \%$.[12] As shown in Fig. 6(b), the viscosities of the AAILs became lower than $10 \mathrm{mPa} \cdot \mathrm{s}$; therefore, the variation of viscosity with increasing $\mathrm{RH}$ became negligible. Furthermore, the trans-membrane concentration gradient of the $\mathrm{CO}_{2}$ complex was constant over the entire $\mathrm{RH}$ range because the amino groups of the glycinate anions in $\left[\mathrm{N}_{1111}\right][\mathrm{Gly}]$ and [ $\left.\mathrm{N}_{4444}\right][\mathrm{Gly}]$ can fully react with $\mathrm{CO}_{2}$ regardless of the $\mathrm{RH}$. Therefore, the $\mathrm{CO}_{2}$ permeabilities of [ $\left.\mathrm{N}_{1111}\right][\mathrm{Gly}]$ - and [ $\left.\mathrm{N}_{4444}\right][\mathrm{Gly}]$-based FTMs became almost constant under high $\mathrm{RH}$ conditions. However, the $\left[\mathrm{N}_{1111}\right][\mathrm{Gly}]$-based FTM showed higher $\mathrm{CO}_{2}$ permeability than the [ $\left.\mathrm{N}_{4444}\right]$ [Gly]-based FTM; this is due to differences in the $\mathrm{CO}_{2}$ absorption amount resulting from differences in the amino-group densities of the AAILs, as shown in Fig. 8(b).

For the $\left[\mathrm{aN}_{111}\right][\mathrm{Gly}]$-based FTMs, the relationships between the $\mathrm{CO}_{2}$ permeability and $\mathrm{RH}$ 
differed from the other two AAIL-based FTMs. Although the $\mathrm{CO}_{2}$ permeability of the [aN $\mathrm{a}_{111}$ [Gly]-based FTMs under low RH conditions indicated almost the same trend as that of the [ $\left.\mathrm{N}_{1111}\right][\mathrm{Gly}]$-based FTMs, it continuously and monotonically increased with increasing RH even under high RH conditions. This result could be explained by the effect of the additional amino group in the cation of [aN $\left.\mathrm{an}_{111}\right][\mathrm{Gly}]$. As shown in Fig. 8(c), the amino groups in the cation and anion of [aN $\left.\mathrm{a}_{111}\right][\mathrm{Gly}]$ would react with $\mathrm{CO}_{2}$ under saturated water vapor pressure conditions. Therefore, the $\mathrm{CO}_{2}$ permeability of the [aN $\left.\mathrm{N}_{111}\right][\mathrm{Gly}]$-based FTM was higher than that of the $\left[\mathrm{N}_{1111}\right][\mathrm{Gly}]$-based FTM under high RH conditions. In contrast, under low $\mathrm{RH}$ conditions, the $\mathrm{CO}_{2}$ permeabilities of [aN $\left.\mathrm{N}_{111}\right][\mathrm{Gly}]-$ and [ $\left.\mathrm{N}_{1111}\right][\mathrm{Gly}]$-based FTMs were almost equivalent. From this trend, it could be suggested that one of the amino groups in $\left[\mathrm{aN}_{111}\right][\mathrm{Gly}]$ might not react with $\mathrm{CO}_{2}$ and therefore not affect $\mathrm{CO}_{2}$ permeation in the low $\mathrm{RH}$ region.

The effect of $\mathrm{RH}$ on the $\mathrm{CO}_{2}$ reactivity of $\left[\mathrm{aN}_{111}\right][\mathrm{Gly}]$ can be elucidated by evaluating the difference between the amounts of $\mathrm{CO}_{2}$ absorbed under dry and humid conditions in the $\mathrm{CO}_{2}$ absorption tests. However, it was quite difficult to measure the $\mathrm{CO}_{2}$ absorption under dry conditions because the viscosity of $\left[\mathrm{aN}_{111}\right][\mathrm{Gly}]$ markedly increased with $\mathrm{CO}_{2}$ absorption. Therefore, we investigated the effect of $\mathrm{RH}$ on the reactivities of the AAILs with $\mathrm{CO}_{2}$ using DFT studies. Regarding [aN $\left.{ }_{111}\right][\mathrm{Gly}]$, the formation of three types of [aN $\left.\mathrm{a}_{111}\right][\mathrm{Gly}]-\mathrm{CO}_{2}$ complexes is possible: 1 ) $\mathrm{COM}_{\mathrm{C}}$, which could form via a reaction between $\mathrm{CO}_{2}$ and the amino group in the cation of [aN $\mathrm{a}_{111}$ [Gly] (Fig. S2(a)); 2) $\mathrm{COM}_{\mathrm{A}}$, which could form via a reaction between $\mathrm{CO}_{2}$ and an amino group in the anion of [aN $\left.\mathrm{aN}_{111}\right]$ [Gly] (Fig. S2(b)); and 3) $\mathrm{COM}_{\mathrm{CA}}$, which could form via a reaction between $\mathrm{CO}_{2}$ and the amino groups in both the cation and anion of [aN $\left.\mathrm{a}_{111}\right][\mathrm{Gly}]$ (Fig. S2(c)). The binding energies of these complexes under dry and humid conditions were calculated via DFT, and we investigated the structures of the complexes under each condition on the basis of the structural stability predicted from the binding energy. The binding energies of the three complexes under dry and humid conditions are listed in Table 3; the results show that the binding energies under both dry and humid conditions were in the following order: $\mathrm{COM}_{\mathrm{C}}<\mathrm{COM}_{\mathrm{CA}}<\mathrm{COM}_{\mathrm{A}}$. In general, it is well known that a structure with a smaller binding energy (large negative value) is more stable. Therefore, the stabilities of the complexes under both dry and humid conditions were in the following order: $\mathrm{COM}_{\mathrm{C}}>\mathrm{COM}_{\mathrm{CA}}>\mathrm{COM}_{\mathrm{A}}$.

Based on the above explanations, the binding energies of $\mathrm{COM}_{\mathrm{A}}$ and $\mathrm{COM}_{\mathrm{CA}}$ were significantly different from that of $\mathrm{COM}_{C}$ under dry conditions. The binding energy difference between $\mathrm{COM}_{C}$ and $\mathrm{COM}_{\mathrm{A}}$ under dry conditions was $-36.48 \mathrm{kcal} / \mathrm{mol}$, and that between $\mathrm{COM}_{\mathrm{C}}$ and $\mathrm{COM}_{\mathrm{CA}}$ was $-16.87 \mathrm{kcal} / \mathrm{mol}$. In contrast, the binding energy of $\mathrm{COM}_{\mathrm{CA}}$ was similar to that of $\mathrm{COM}_{\mathrm{C}}$ and much smaller than that of $\mathrm{COM}_{\mathrm{A}}$ under humid conditions. The binding energy difference between $\mathrm{COM}_{\mathrm{C}}$ and $\mathrm{COM}_{\mathrm{CA}}$ under humid conditions was only $-3.71 \mathrm{kcal} / \mathrm{mol}$. From these results, $\mathrm{COM}_{\mathrm{C}}$ would preferentially form under dry conditions, while $\mathrm{COM}_{\mathrm{C}}$ and $\mathrm{COM}_{\mathrm{CA}}$ would co-exist under humid 
conditions. Thus, the amount of $\mathrm{CO}_{2}$ absorbed in [aN $\left.\mathrm{an}_{111}\right][\mathrm{Gly}]$ is expected to increase due to the formation of $\mathrm{COM}_{\mathrm{CA}}$ under high $\mathrm{RH}$ conditions, which leads to the observed continuous increase in $\mathrm{CO}_{2}$ permeability. The continuous increase in the $\mathrm{CO}_{2}$ permeability of [aN $\left.\mathrm{a}_{111}\right][\mathrm{Gly}]-\mathrm{FTM}$ above $50 \%$ RH shown in Fig. 10(a) was caused by this additional reaction of $\mathrm{CO}_{2}$ with $\mathrm{COM}_{\mathrm{C}}$ to form $\mathrm{COM}_{\mathrm{CA}}$.

In contrast, as shown in Fig. 10(b), the $\mathrm{N}_{2}$ permeabilities of the AAIL-FTMs monotonically increased with RH; this is because the viscosities of each AAIL decreased with increasing water content in the AAILs, as shown in Fig. 6(b). The $\mathrm{N}_{2}$ permeabilities of the $\left[\mathrm{N}_{1111}\right][\mathrm{Gly}]$ - and $\left[\mathrm{aN}_{111}\right][\mathrm{Gly}]$-based FTMs were similar at all $\mathrm{RH}$ values and lower than that of the [ $\left.\mathrm{N}_{4444}\right][\mathrm{Gly}]$-based FTM. The difference in the $\mathrm{N}_{2}$ permeabilities is caused by a difference in the $\mathrm{N}_{2}$ absorption amount, which is dependent on the FFVs of the AAILs (Fig. 8(a)). Regarding $\mathrm{CO}_{2} / \mathrm{N}_{2}$ selectivity, as shown in Fig. 10(c), the [aN $\left.\mathrm{N}_{111}\right][\mathrm{Gly}]$ - and $\left[\mathrm{N}_{1111}\right][\mathrm{Gly}]$-based FTMs showed higher $\mathrm{CO}_{2} / \mathrm{N}_{2}$ selectivity than the [ $\left.\mathrm{N}_{4444}\right][\mathrm{Gly}]$-based FTM owing to their smaller FFVs and higher amino-group densities compared to those of $\left[\mathrm{N}_{4444}\right][\mathrm{Gly}]$. Under high $\mathrm{RH}$ conditions, the $\mathrm{CO}_{2} / \mathrm{N}_{2}$ selectivity of the $\left[\mathrm{aN}_{111}\right][\mathrm{Gly}]$-based FTM was higher than that of the $\left[\mathrm{N}_{1111}\right][\mathrm{Gly}]$-based FTM, which was caused by the increased $\mathrm{CO}_{2}$ absorption by the second amino group under highly humid conditions.

From the results of this study, the following design criteria for AAILs as effective $\mathrm{CO}_{2}$ carriers in FTMs under humid conditions are proposed: (1) Multi-amino-functionalization of AAILs, which enhances $\mathrm{CO}_{2}$ permeability, and (2) small molecular size, which not only decreases $\mathrm{N}_{2}$ permeability but also enhances $\mathrm{CO}_{2}$ permeability. Because the $\left[\mathrm{aN}_{111}\right][\mathrm{Gly}]$-based FTM developed in this study was a supported ionic liquid membrane in which $\left[\mathrm{aN}_{111}\right][\mathrm{Gly}]$ was impregnated in a porous support membrane by weak capillary force, there still remains challenge on the improvement of low pressure resistance and the achievement of long term stability. Recently, we developed a tough gel membrane containing a large amount of AAILs with high pressure resistance and long term stability.[38] The tough gel technology could be used to prepare $\left[\mathrm{aN}_{111}\right][\mathrm{Gly}]$-based gel membrane with high pressure resistance and good stability. Fabrication of a tough gel membrane containing a large amount of [aN $\left.\mathrm{a}_{111}\right][\mathrm{Gly}]$ for practical application is our next target.

\section{Conclusions}

Three AAILs with different numbers of amino groups and different molecular sizes were synthesized, and their gas absorption properties were investigated. The FFVs of the AAILs before and after $\mathrm{CO}_{2}$ absorption were calculated using MD simulations, and the amounts of $\mathrm{N}_{2}$ absorbed were evaluated on the basis of their FFVs. Based on computational and experimental studies, it was determined that the FFVs and molar volumes of the AAILs decreased with decreasing size of the ionic liquids. [aN $\left.\mathrm{a}_{111}\right][\mathrm{Gly}]$, which is small and contains two amino groups, showed high $\mathrm{CO}_{2}$ and low $\mathrm{N}_{2}$ absorptions with a low viscosity under humid conditions, as aided by water molecules. 
AAIL-based FTMs were prepared and their gas permeation properties were investigated. Based on the experimental and computational results, it was suggested that an additional $\left[\mathrm{aN}_{111}\right][\mathrm{Gly}]-\mathrm{CO}_{2}$ complex can form via a reaction with the second amino group at higher RHs. The [ $\left.\mathrm{aN}_{111}\right][\mathrm{Gly}]$-based FTM showed high $\mathrm{CO}_{2}$ permeability and high $\mathrm{CO}_{2}$ selectivity against $\mathrm{N}_{2}$ over a wide $\mathrm{RH}$ range. This membrane selectively permeated $\mathrm{CO}_{2}$ based on the facilitated transport mechanism. Therefore, it is expected that this membrane can effectively separate $\mathrm{CO}_{2}$ from not only $\mathrm{N}_{2}$ but also $\mathrm{O}_{2}, \mathrm{CH}_{4}$ and $\mathrm{H}_{2}$, which permeate through the membrane based on the simple solution-diffusion mechanism. From the investigations, as the design criteria for AAILs as suitable $\mathrm{CO}_{2}$ carriers for FTMs under humid conditions, compact and multi-amino-functionalized AAILs are recommended.

\section{Acknowledgements}

This work was supported by the Japan Society for the Promotion of Science (JSPS) KAKENHI (Grant No. 25•4070) and Japan Science and Technology Agency-Advanced Low Carbon Technology Research and Development Program (JST-ALCA).

\section{References}

[1] B. Li, Y. Duan, D. Luebke, B. Morreale, Advances in $\mathrm{CO}_{2}$ capture technology: A patent review, Appl. Energy, 102 (2013) 1439-1447.

[2] L.M. Robeson, The upper bound revisited, J. Membr. Sci., 320 (2008) 390-400.

[3] Z. Dai, R. D. Noble, D. L. Gin, X. Zhang, L. Deng, Combination of ionic liquids with membrane technology: A new approach for $\mathrm{CO}_{2}$ separation, J. Membr. Sci., 497 (2016) 1-20.

[4] M. Teramoto, K. Nakai, N. Ohnishi, Q. Huang, T. Watari, H. Matsuyama, Facilitated Transport of Carbon Dioxide through Supported Liquid Membranes of Aqueous Amine Solutions, Ind. Eng. Chem. Res., 35 (1996) 538-545.

[5] A.S. Kovvali, H. Chen, K.K. Sirkar, Dendrimer Membranes: A CO${ }_{2}$-Selective Molecular Gate, J. Am. Chem. Soc., 122 (2000) 7594-7595.

[6] J. Huang, J. Zou, W.S.W. Ho, Carbon Dioxide Capture Using a $\mathrm{CO}_{2}$-Selective Facilitated Transport Membrane, Ind. Eng. Chem. Res., 47 (2008) 1261-1267.

[7] H. Kreulen, C.A. Smolders, G.F. Versteeg, W.P.M. Swaaij, Selective removal of hydrogen sulfide from sour gases with microporous membranes. Part II. A liquid membrane of water-free tertiary amines, $J$. Membr. Sci., 82 (1993) 185-197.

[8] M.G. Shalygin, D. Roizard, E. Favre, V.V. Teplyakov, $\mathrm{CO}_{2}$ transfer in an aqueous potassium carbonate liquid membrane module with dense polymeric supporting layers: Influence of concentration, circulation flow rate and temperature, J. Membr. Sci., 318 (2008) 317-326.

[9] L.A. El-Azzami, E.A. Grulke, Carbon dioxide separation from hydrogen and nitrogen, J. Membr. Sci., 328 (2009) 15-22. 
[10] A.S. Kovvali, K.K. Sirkar, Dendrimer Liquid Membranes: $\mathrm{CO}_{2}$ Separation from Gas Mixtures, Ind. Eng. Chem. Res., 40 (2001) 2502-2511.

[11] S. Kasahara, E. Kamio, T. Ishigami, H. Matsuyama, Amino acid ionic liquid-based facilitated transport membranes for $\mathrm{CO}_{2}$ separation, Chem. Commun. (Cambridge, U. K.), 48 (2012) 6903-6905.

[12] S. Kasahara, E. Kamio, T. Ishigami, H. Matsuyama, Effect of water in ionic liquids on $\mathrm{CO}_{2}$ permeability in amino acid ionic liquid-based facilitated transport membranes, J. Membr. Sci., 415-416 (2012) 168-175.

[13] S. Kasahara, E. Kamio, H. Matsuyama, Improvements in the $\mathrm{CO}_{2}$ permeation selectivities of amino acid ionic liquid-based facilitated transport membranes by controlling their gas absorption properties, $J$. Membr. Sci., 454 (2014) 155-162.

[14] S. Kasahara, E. Kamio, A. Otani, H. Matsuyama, Fundamental Investigation of the Factors Controlling the $\mathrm{CO}_{2}$ Permeability of Facilitated Transport Membranes Containing Amine-Functionalized Task-Specific Ionic Liquids, Ind. Eng. Chem. Res., 53 (2014) 2422-2431.

[15] K. Fukumoto, M. Yoshizawa, H. Ohno, Room Temperature Ionic Liquids from 20 Natural Amino Acids, J. Am. Chem. Soc., 127 (2005) 2398-2399.

[16] J. Zhang, S. Zhang, K. Dong, Y. Zhang, Y. Shen, X. Lv, Supported absorption of $\mathrm{CO}_{2}$ by tetrabutylphosphonium amino acid ionic liquids, Chem. - Eur. J., 12 (2006) 4021-4026.

[17] B.F. Goodrich, J.C. de la Fuente, B.E. Gurkan, Z.K. Lopez, E.A. Price, Y. Huang, J.F. Brennecke, Effect of Water and Temperature on Absorption of $\mathrm{CO}_{2}$ by Amine-Functionalized Anion-Tethered Ionic Liquids, J. Phys. Chem. B, 115 (2011) 9140-9150.

[18] Y. Zhang, S. Zhang, X. Lu, Q. Zhou, W. Fan, X.P. Zhang, Dual amino-functionalised phosphonium ionic liquids for $\mathrm{CO}_{2}$ capture, Chem. - Eur. J., 15 (2009) 3003-3011.

[19] M.S. Shannon, J.M. Tedstone, S.P.O. Danielsen, M.S. Hindman, A.C. Irvin, J.E. Bara, Free Volume as the Basis of Gas Solubility and Selectivity in Imidazolium-Based Ionic Liquids, Ind. Eng. Chem. Res., 51 (2012) 5565-5576.

[20] T.C. Lourenco, M.F.C. Coelho, T.C. Ramalho, D. van der Spoel, L.T. Costa, Insights on the Solubility of $\mathrm{CO}_{2}$ in 1-Ethyl-3-methylimidazolium Bis(trifluoromethylsulfonyl)imide from the Microscopic Point of View, Environ. Sci. Technol., 47 (2013) 7421-7429.

[21] Modeling and Simulation Solutions for Chemicals and Materials Research, Materials Studio (Version 6.1), Accelrys software Inc., San Diego, USA (2013) www.accelrys.com.

[22] G.W.T. M. J. Frisch, H. B. Schlegel, G. E. Scuseria, M. A. Robb, J. R. Cheeseman, G. Scalmani, V. Barone, B. Mennucci, G. A. Petersson, H. Nakatsuji, M. Caricato, X. Li, H. P. Hratchian, A. F. Izmaylov, J. Bloino, G. Zheng, J. L. Sonnenberg, M. Hada, M. Ehara, K. Toyota, R. Fukuda, J. Hasegawa, M. Ishida, T. Nakajima, Y. Honda, O. Kitao, H. Nakai, T. Vreven, J. A. Montgomery, J. E. Peralta, F. Ogliaro, M. Bearpark, J. J. Heyd, E. Brothers, K. N. Kudin, V. N. Staroverov, R. Kobayashi, J. Normand, K. aghavachari, A. Rendell, J. C. Burant, S. S. Iyengar, J. Tomasi, M. Cossi, N. Rega, J. M. Millam, M. 
Klene, J. E. Knox, J. B. Cross, V. Bakken, C. Adamo, J. Jaramillo, R. Gomperts, R. E. Stratmann, O. Yazyev, A. J. Austin, R. Cammi, C. Pomelli, J. W. Ochterski, R. L. Martin, K. Morokuma, V. G. Zakrzewski, G. A. Voth, P. Salvador, J. J. Dannenberg, S. Dapprich, A. D. Daniels, Farkas, J. B. Foresman, J. V. Ortiz, J. Cioslowski and D. J. Fox, Gaussian 09, Revision A.02, Gaussian, Inc.: Wallingford, CT, (2009).

[23] F.-Y. Dupradeau, A. Pigache, T. Zaffran, C. Savineau, R. Lelong, N. Grivel, D. Lelong, W. Rosanski,

P. Cieplak, The R.E.D. tools: advances in RESP and ESP charge derivation and force field library building, Phys. Chem. Chem. Phys., 12 (2010) 7821-7839.

[24] T.A.D. D. Case, T. E. Cheatham, C. Simmerling, J. Wang, R. Duke, R. Luo, M. Crowley, R. Walker, W. Zhang, K. M. Merz, B. Wang, S. Hayik, A. Roitberg, G. Seabra, I. Kolossvary, K. F. Wong, F. Paesani, J. Vanicek, X. Wu, S. Brozell, T. Steinbrecher, H. Gohlke, L. Yang, C. Tan, J. Mongan, V. Hornak, G. Cui, D. H. Mathews, M. G. Seetin, C. Sagui, V. Babin and P. Kollman, Amber 11. .San Francisco, CA: University of California; 2010.

[25] L. Martinez, R. Andrade, E.G. Birgin, J.M. Martinez, PACKMOL: A package for building initial configurations for molecular dynamics simulations, J. Comput. Chem., 30 (2009) 2157-2164.

[26] E.L. D. van der Spoel, B. Hess, A. R. van Buuren, E. Apol, P. J. Meulenhoff, D. P. Tieleman, A. L. T. M. Sijbers, K. A. Feenstra, R. van Drunen and H. J. C. Berendsen, Gromacs User Manual version 4.5.6, Www.gromacs.org (2010).

[27] G. Bussi, D. Donadio, M. Parrinello, Canonical sampling through velocity rescaling, J. Chem. Phys., 126 (2007) 014101-014107.

[28] H.J.C. Berendsen, J.P.M. Postma, W.F. Van Gunsteren, A. DiNola, J.R. Haak, Molecular dynamics with coupling to an external bath, J. Chem. Phys., 81 (1984) 3684-3690.

[29] U. Essmann, L. Perera, M.L. Berkowitz, T. Darden, H. Lee, L.G. Pedersen, A smooth particle mesh Ewald method, J. Chem. Phys., 103 (1995) 8577-8593.

[30] W. Humphrey, A. Dalke, K. Schulten, VDM: visual molecular dynamics, J. Mol. Graphics, 14 (1996) 33-38.

[31] V.S. Bernales, A.V. Marenich, R. Contreras, C.J. Cramer, D.G. Truhlar, Quantum Mechanical Continuum Solvation Models for Ionic Liquids, J. Phys. Chem. B, 116 (2012) 9122-9129.

[32] E.I. Izgorodina, U.L. Bernard, D.R. MacFarlane, Ion-Pair Binding Energies of Ionic Liquids: Can DFT Compete with Ab Initio-Based Methods?, J. Phys. Chem. A, 113 (2009) 7064-7072.

[33] A.V. Marenich, C.J. Cramer, D.G. Truhlar, Universal Solvation Model Based on Solute Electron Density and on a Continuum Model of the Solvent Defined by the Bulk Dielectric Constant and Atomic Surface Tensions, J. Phys. Chem. B, 113 (2009) 6378-6396.

[34] W.M. Lee, Selection of barrier materials from molecular structure, Polym. Eng. Sci., 20 (1980) 65-69.

[35] A. Bondi, van der Waals volumes and radii, J. Phys. Chem., 68 (1964) 441-451. 
[36] B.F. Goodrich, J.C. de la Fuente, B.E. Gurkan, D.J. Zadigian, E.A. Price, Y. Huang, J.F. Brennecke, Experimental Measurements of Amine-Functionalized Anion-Tethered Ionic Liquids with Carbon Dioxide, Ind. Eng. Chem. Res., 50 (2011) 111-118.

[37] K.E. Gutowski, E.J. Maginn, Amine-Functionalized Task-Specific Ionic Liquids: A Mechanistic Explanation for the Dramatic Increase in Viscosity upon Complexation with $\mathrm{CO}_{2}$ from Molecular Simulation, J. Am. Chem. Soc., 130 (2008) 14690-14704.

[38] M. Moghadam, E. Kamio, A. Yoshizumi, H. Matsuyama, An Amino Acid Ionic Liquid-based Tough Ion Gel Membrane for $\mathrm{CO}_{2}$ Capture, Chem. Commun., 51 (2015) 13658-13661. 
Table 1 Experimental conditions for the gas permeation tests

(a) $\mathrm{CO}_{2}$ partial pressure dependency measurement

\begin{tabular}{|c|c|c|}
\hline Temperature & & $373 \mathrm{~K}$ \\
\hline \multirow[t]{2}{*}{ Pressure } & Feed & $101.3 \mathrm{kPa}$ \\
\hline & Sweep & $101.3 \mathrm{kPa}$ \\
\hline \multirow[t]{2}{*}{ Partial pressure difference } & $\mathrm{CO}_{2}$ & $2,2.5,5,10$ and $25 \mathrm{kPa}$ \\
\hline & $\mathrm{N}_{2}$ & 98, 97.5, 95, 90 and $75 \mathrm{kPa}$ \\
\hline \multicolumn{2}{|l|}{ Total pressure difference } & $0 \mathrm{kPa}$ \\
\hline \multicolumn{3}{|l|}{ Gas flow rate (dry base) } \\
\hline \multirow[t]{3}{*}{ Feed } & Total & $200 \mathrm{~cm}^{3} / \mathrm{min}$ \\
\hline & $\mathrm{CO}_{2}$ & $4,5,10,20,50 \mathrm{~cm}^{3} / \mathrm{min}$ \\
\hline & $\mathrm{N}_{2}$ & Balance \\
\hline Sweep & $\mathrm{He}$ & $40 \mathrm{~cm}^{3} / \min$ \\
\hline \multicolumn{2}{|l|}{ Relative humidity } & $0 \%$ (dry condition) \\
\hline \multicolumn{3}{|c|}{ (b) relative humidity dependency measurement } \\
\hline \multicolumn{2}{|l|}{ Temperature } & $373 \mathrm{~K}$ \\
\hline \multirow[t]{2}{*}{ Pressure } & Feed & $101.3 \mathrm{kPa}$ \\
\hline & Sweep & $101.3 \mathrm{kPa}$ \\
\hline \multirow{2}{*}{$\begin{array}{l}\text { Partial pressure difference } \\
\text { Total pressure difference }\end{array}$} & $\mathrm{CO}_{2}$ & $1 \mathrm{kPa}$ \\
\hline & & $0 \mathrm{kPa}$ \\
\hline \multicolumn{3}{|l|}{ Gas flow rate (dry base) } \\
\hline \multirow[t]{3}{*}{ Feed } & Total & $200 \mathrm{~cm}^{3} / \mathrm{min}$ \\
\hline & $\mathrm{CO}_{2}$ & $2 \mathrm{~cm}^{3} / \mathrm{min}$ \\
\hline & $\mathrm{N}_{2}$ & Balance \\
\hline Sweep & $\mathrm{He}$ & $40 \mathrm{~cm}^{3} / \mathrm{min}$ \\
\hline Relative humidity & & $0,2.7,5.3$ 10-90\% (every 10\%) \\
\hline
\end{tabular}


Table 2 FFVs and densities of the AAILs from molecular dynamics simulations at $300 \mathrm{~K}$

\begin{tabular}{c|ccc|cc}
\hline & \multicolumn{3}{|c|}{$\begin{array}{c}\text { Before } \mathrm{CO}_{2} \text { absorption under } \\
\text { dry condition }\end{array}$} & \multicolumn{2}{c}{ After $\mathrm{CO}_{2}$ absorption under } \\
& $\mathrm{FFV}\left(\mathrm{SD}^{\dagger}\right)$ & $\begin{array}{c}\rho_{\text {calced }} \\
\left(\mathrm{g} / \mathrm{cm}^{3}\right)\end{array}$ & $\begin{array}{c}\rho_{\text {exp }} \\
\left(\mathrm{g} / \mathrm{cm}^{3}\right)\end{array}$ & $\mathrm{FFV}\left(\mathrm{SD}^{\dagger}\right)$ & $\begin{array}{c}\rho_{\text {calced }} \\
\left(\mathrm{g} / \mathrm{cm}^{3}\right)\end{array}$ \\
\hline$\left[\mathrm{N}_{4444}\right][\mathrm{Gly}]$ & $0.19(0.0058)$ & 0.905 & 0.955 & $0.16(0.012)$ & 1.022 \\
{$\left[\mathrm{~N}_{1111}\right][\mathrm{Gly}]$} & $0.12(0.010)$ & 1.058 & 1.076 & $0.050(0.0058)$ & 1.311 \\
{$\left[\mathrm{aN}_{111}\right][\mathrm{Gly}]$} & $0.12(0.010)$ & 1.123 & 1.126 & $0.070(0.010)$ & 1.403 \\
\hline
\end{tabular}

${ }^{\dagger} \mathrm{SD}$ means standard deviation. ${ }^{\ddagger}$ The $\rho_{\exp }$ is the experimentally obtained density under dry condition at $303 \mathrm{~K}$. 
Table 3 Binding energies of [aN $\left.\mathrm{a}_{111}\right][\mathrm{Gly}]-\mathrm{CO}_{2}$ complexes

\begin{tabular}{c|c|c}
\hline Complex & $\begin{array}{c}\text { Dry condition } \\
\Delta \mathrm{E}(\mathrm{kcal} / \mathrm{mol})\end{array}$ & $\begin{array}{c}\text { Humid condition } \\
\Delta \mathrm{E}(\mathrm{kcal} / \mathrm{mol})\end{array}$ \\
\hline $\mathrm{COM}_{\mathrm{C}}$ & -130.54 & -16.00 \\
$\mathrm{COM}_{\mathrm{A}}$ & -94.06 & -1.05 \\
$\mathrm{COM}_{\mathrm{CA}}$ & -113.67 & -12.29 \\
\hline
\end{tabular}


(a)

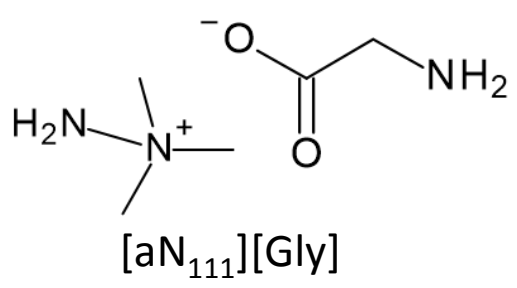

(b)<smiles>COC(=O)CN</smiles>

$\left[\mathrm{N}_{1111}\right][\mathrm{Gly}]$

(c)

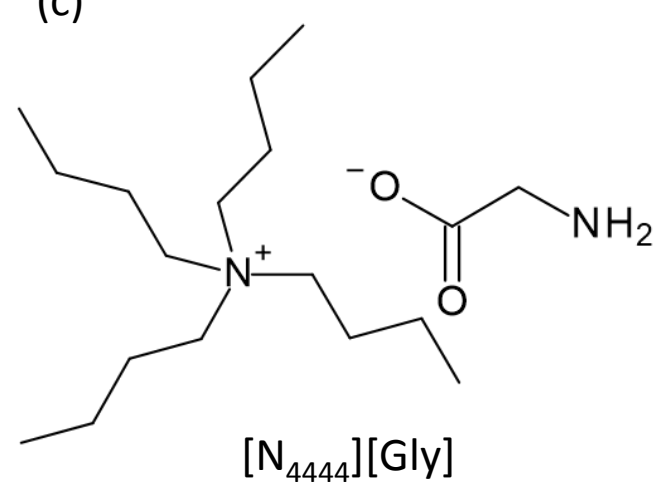

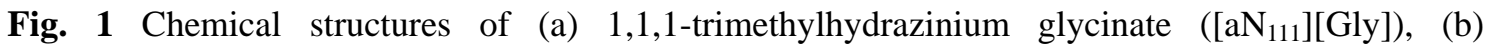
tetramethylammonium glycinate $\left(\left[\mathrm{N}_{1111}\right][\mathrm{Gly}]\right)$, and (c) tetrabutylammonium glycinate ([N $\left.\left.\mathrm{N}_{4444}\right][\mathrm{Gly}]\right)$. 


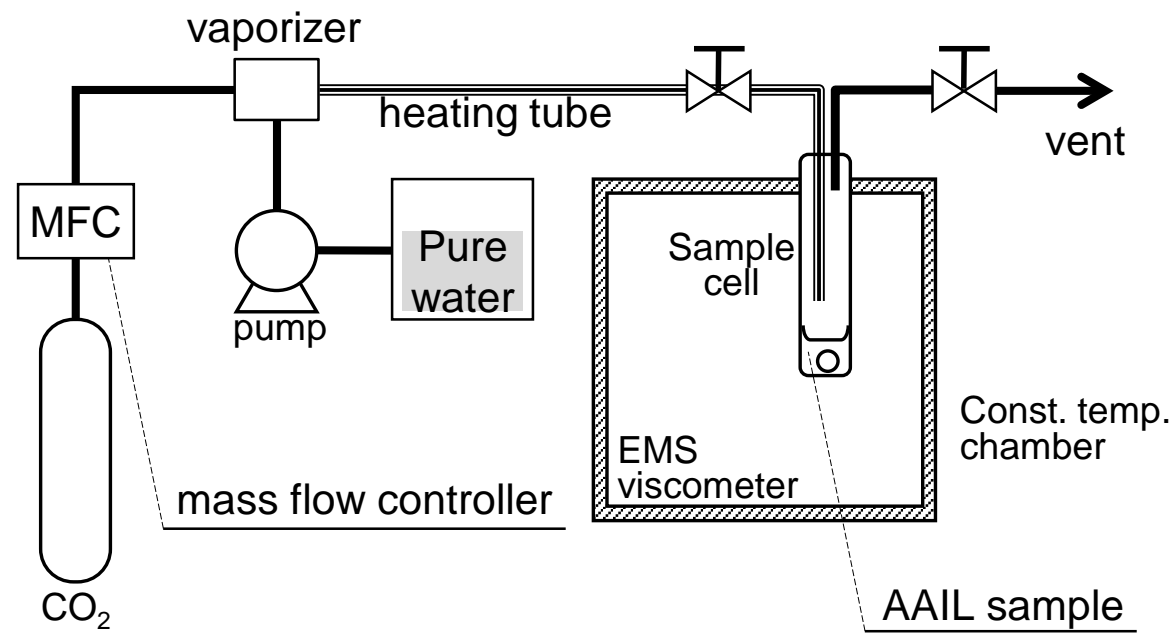

Fig. 2 Schematic diagram of the viscosity measurement system used in this study. 


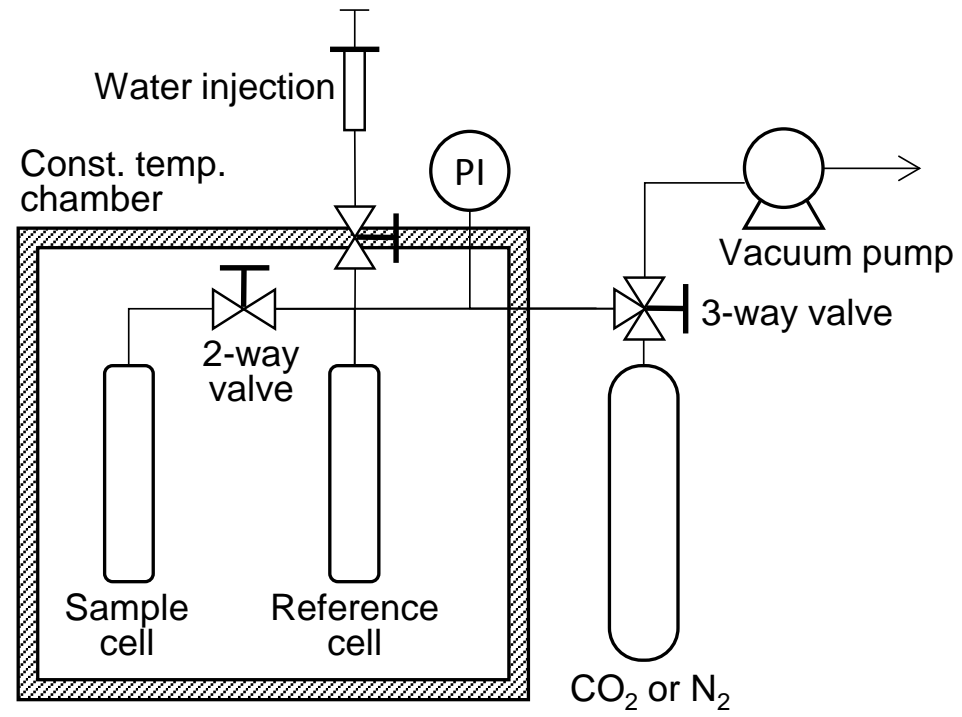

Fig. 3 Schematic diagram of the apparatus used for the gas absorption measurements. 


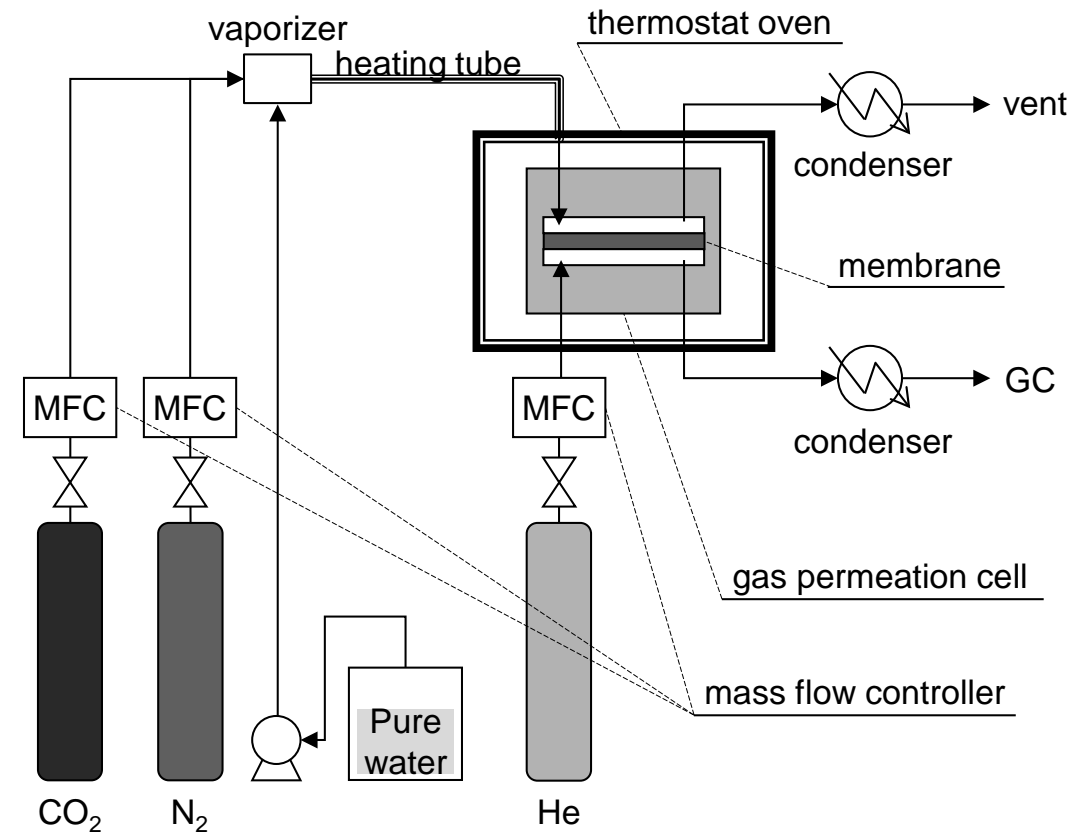

Fig. 4 Schematic diagram of the apparatus for the gas permeation tests. 

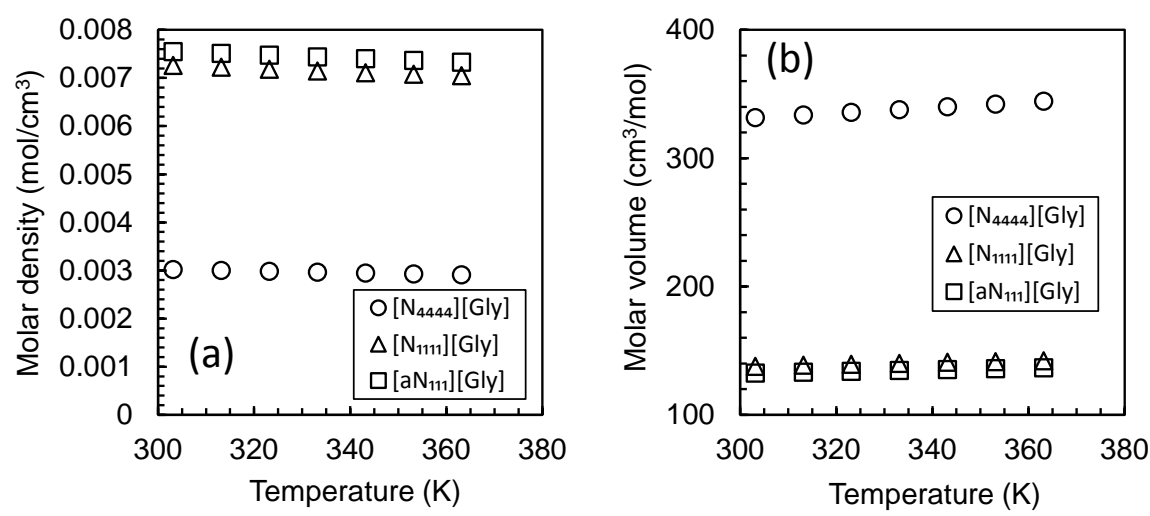

Fig. 5 Effect of temperature on the (a) molar densities and (b) molar volumes of $\left[\mathrm{N}_{4444}\right][\mathrm{Gly}]$, $\left[\mathrm{N}_{1111}\right][\mathrm{Gly}]$, and [aN $\left.\mathrm{a}_{111}\right][\mathrm{Gly}]$. 

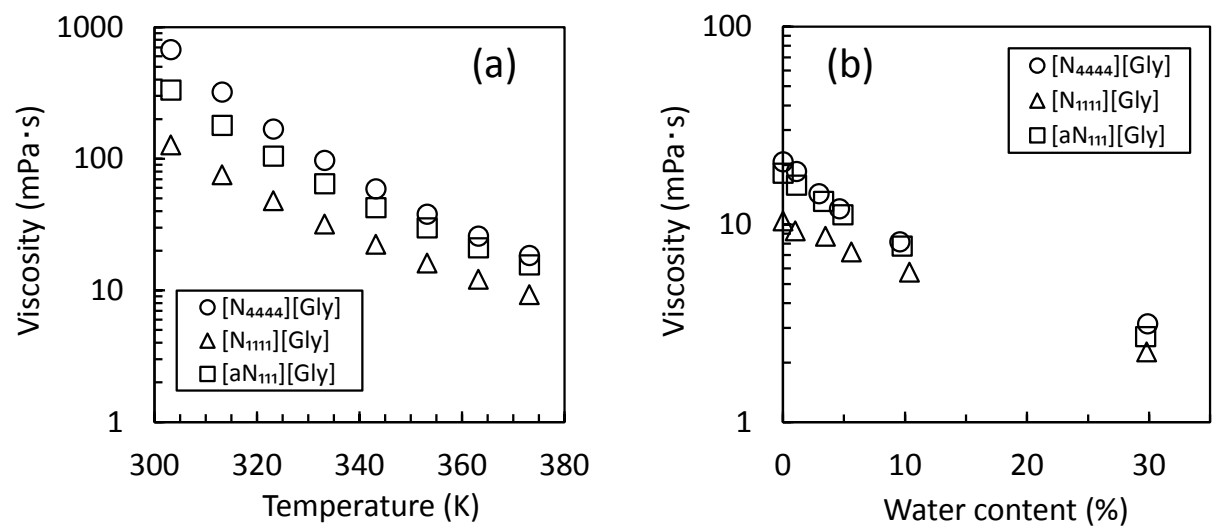

Fig. 6 Effect of (a) temperature and (b) water content on the viscosities of [ $\left.\mathrm{N}_{4444}\right][\mathrm{Gly}]$, [ $\left.\mathrm{N}_{1111}\right][\mathrm{Gly}]$, and $\left[\mathrm{aN}_{111}\right][\mathrm{Gly}]$. The temperature dependency (a) was measured under dry conditions. The effect of water content (b) was investigated at $373 \mathrm{~K}$. 


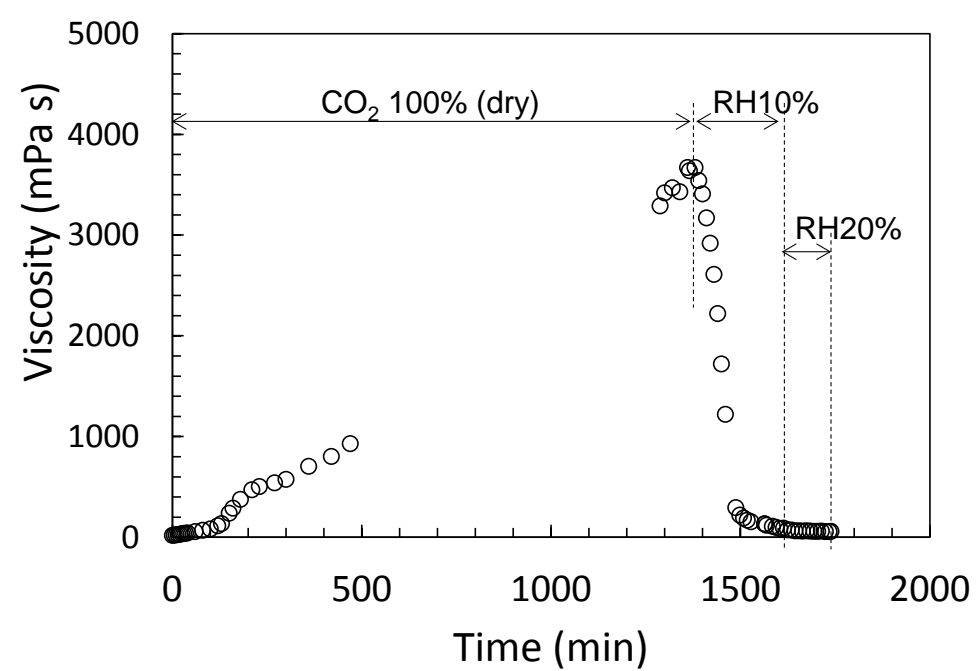

Fig. 7 Effect of RH on the viscosity of $\left[\mathrm{aN}_{111}\right][\mathrm{Gly}]$ in contact with $\mathrm{CO}_{2}$ at $373 \mathrm{~K}$. 

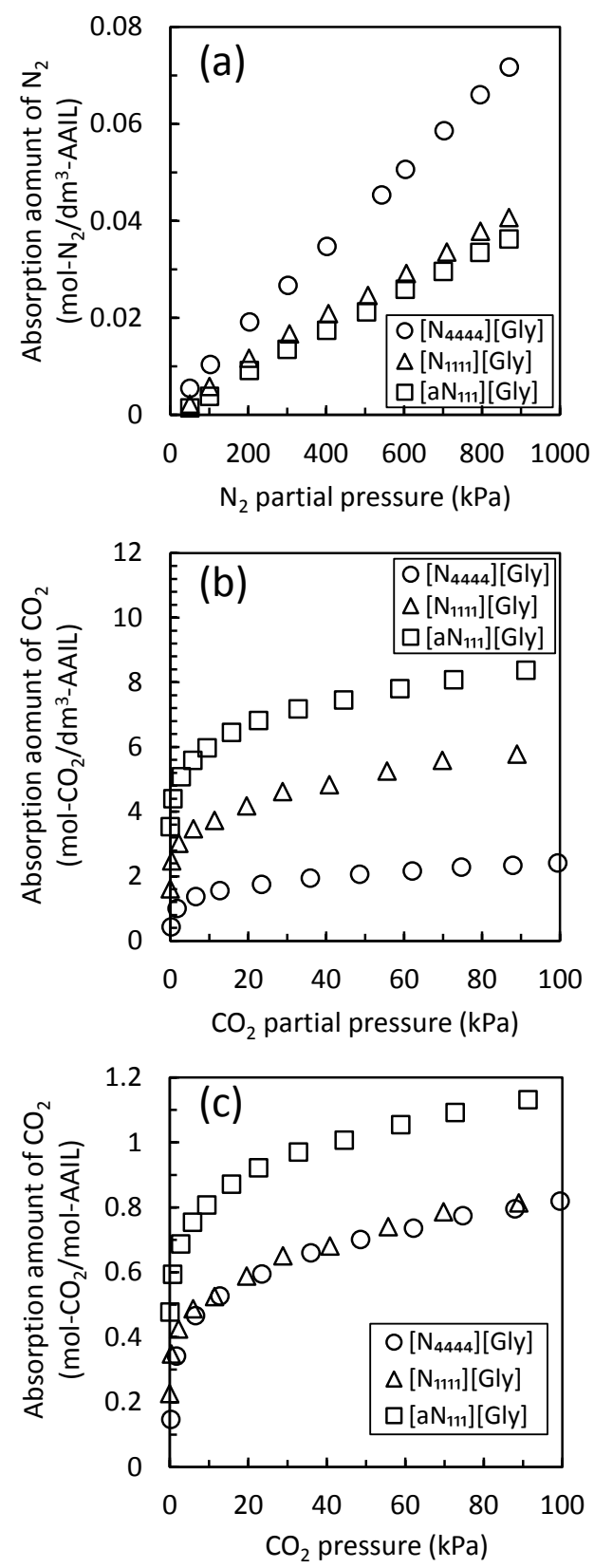

Fig. 8 Absorption isotherms of (a) $\mathrm{N}_{2}\left(\mathrm{~mol} / \mathrm{dm}^{3}\right)$, (b) $\mathrm{CO}_{2}\left(\mathrm{~mol} / \mathrm{dm}^{3}\right.$ ), and (c) $\mathrm{CO}_{2}$ absorbed per mole of AAIL molecules (mol CO $2 / \mathrm{mol} \mathrm{AAIL)}$ at $343 \mathrm{~K}$. 

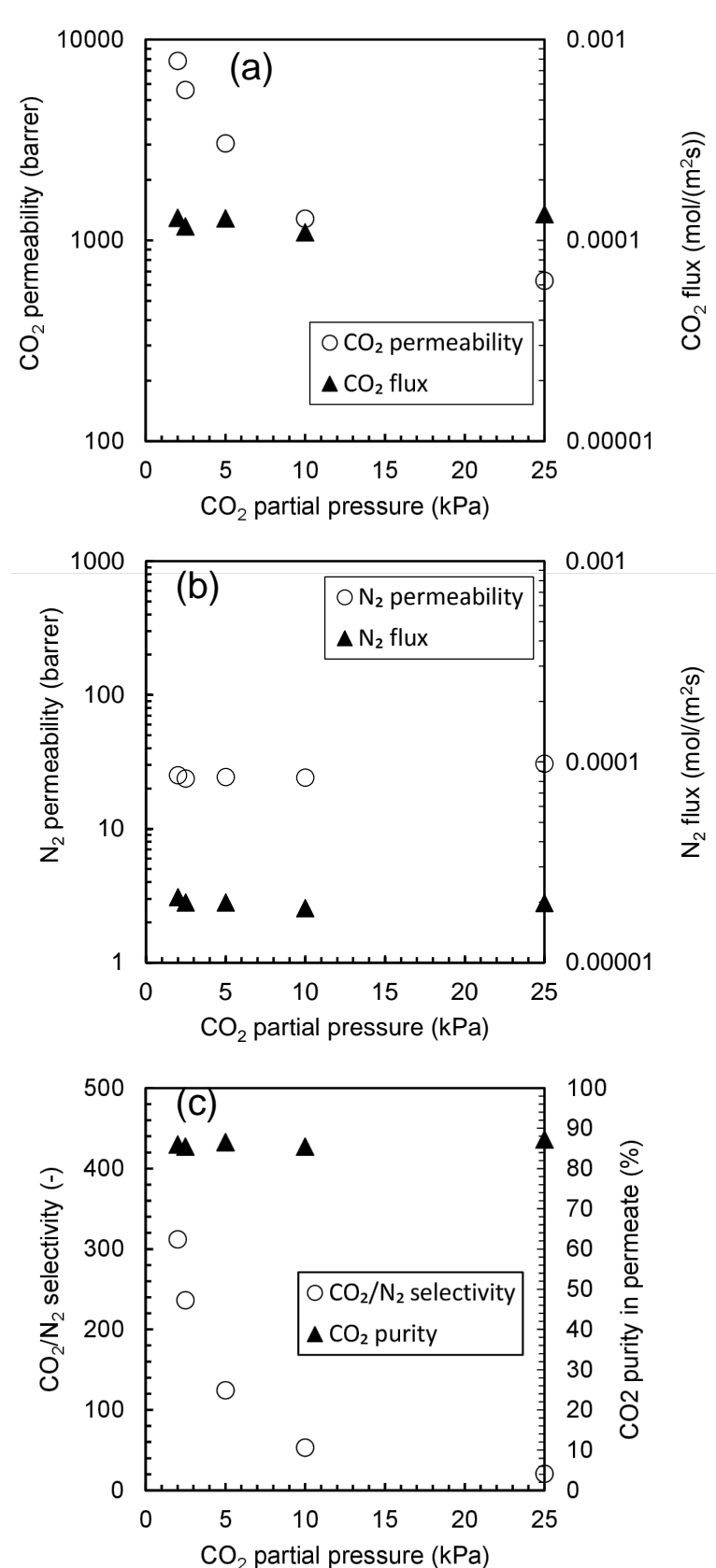

Fig. $9 \mathrm{CO}_{2}$ partial pressure dependency on permeability and flux of (a) $\mathrm{CO}_{2}$ and (b) $\mathrm{N}_{2}$ and (c) $\mathrm{CO}_{2} / \mathrm{N}_{2}$ selectivity and $\mathrm{CO}_{2}$ purity in the permeate of $\left[\mathrm{aN}_{111}\right][\mathrm{Gly}]$-based FTM. Experimental conditions: $T=373 \mathrm{~K}$, Total pressure was atmospheric pressure and the relative humidity in feed gas was $0 \%$ (dry condition). 

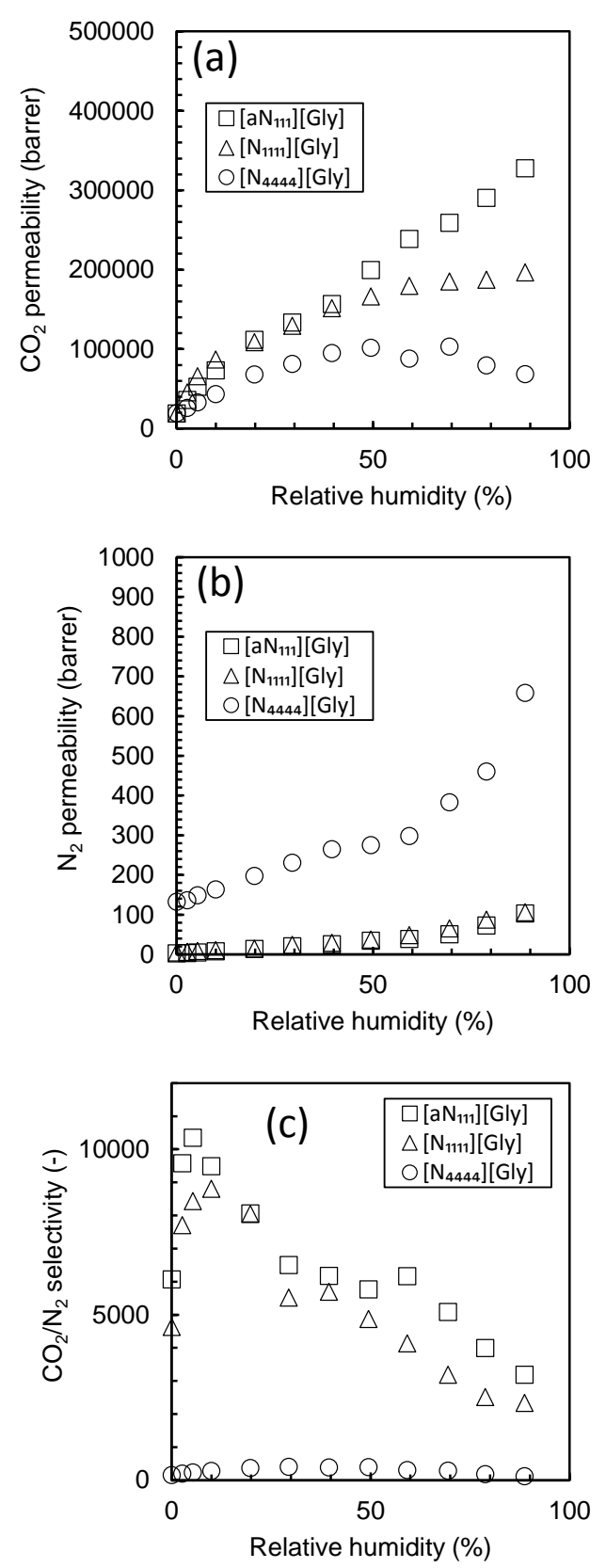

Fig. 10 Effect of relative humidity on the (a) $\mathrm{CO}_{2}$ permeabilities, (b) $\mathrm{N}_{2}$ permeabilities, and (c) $\mathrm{CO}_{2} / \mathrm{N}_{2}$ selectivities of [aN $\left.\mathrm{N}_{111}\right][\mathrm{Gly}]-$, [ $\left.\mathrm{N}_{1111}\right][\mathrm{Gly}]$-, and [ $\left.\mathrm{N}_{4444}\right][\mathrm{Gly}]$-based FTMs $\left(T=373 \mathrm{~K}, p_{\mathrm{CO} 2}=\right.$ $1 \mathrm{kPa})$. 
Graphical Abstract

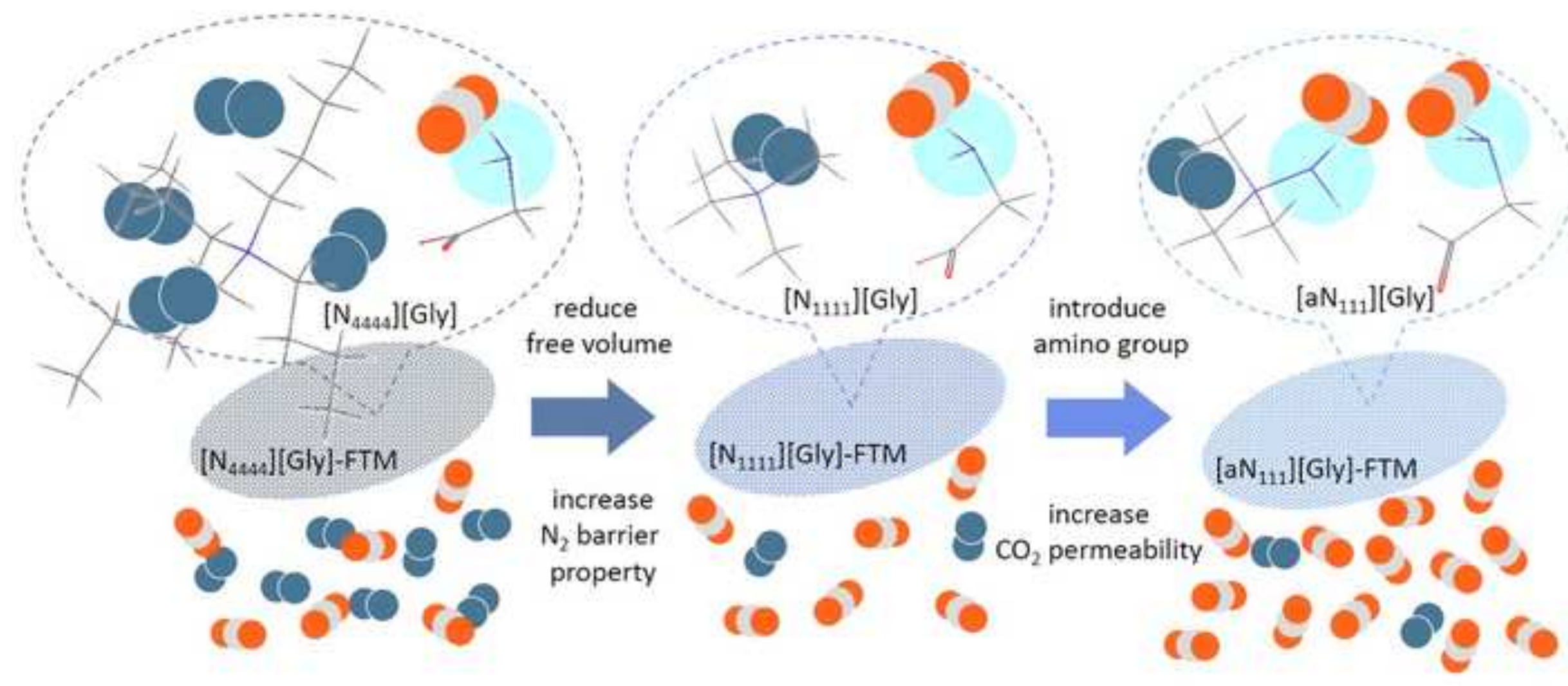

